\title{
TUMOR DESMOIDES EN UNA PACIENTE POST PARTO*
}

\author{
Drs. Víctor Salazar ${ }^{1,2}$, Gonzalo Guíñez ${ }^{1,2}$, Gustavo Vial ${ }^{1,2}$, \\ Juan C. Aguayo ${ }^{2}$, Marcelo Vivanco ${ }^{1,2}$, Hugo Rojas ${ }^{1,2}$ \\ 1 Servicio de Cirugía Adulto. Hospital Padre Alberto Hurtado. \\ 2 Facultad de Medicina Clínica Alemana-Universidad del Desarrollo. \\ Santiago, Chile.
}

\section{Desmoid tumor in a patient postpartum}

Paciente mujer, 26 años de edad, consulta en Servicio de Urgencias al tercer mes postparto por cuadro de dolor y aumento de volumen abdominal periumbilical de rápido crecimiento desde el parto. Al examen físico presenta masa palpable discretamente móvil a nivel periumbilical (Figura 1). El estudio de laboratorio no muestra alteraciones significativas. Se realiza tomografía computada (TC) de abdomen que evidencia masa mesentérica única de 15 x 15 cm dependiente de la arteria mesentérica superior (Figura 2), informe sugerente de tumor desmoides. La colonoscopia no muestra lesiones. Se realiza resección de masa por laparotomía media supra e infraumbilical, respetando la vasculatura intestinal. El diagnóstico anatomopatológico revela un tumor mesentérico, específicamente tumor desmoides de 3.000 g (Figura 3), histológicamente con proliferación mesenquimática fusocelular entremezclada

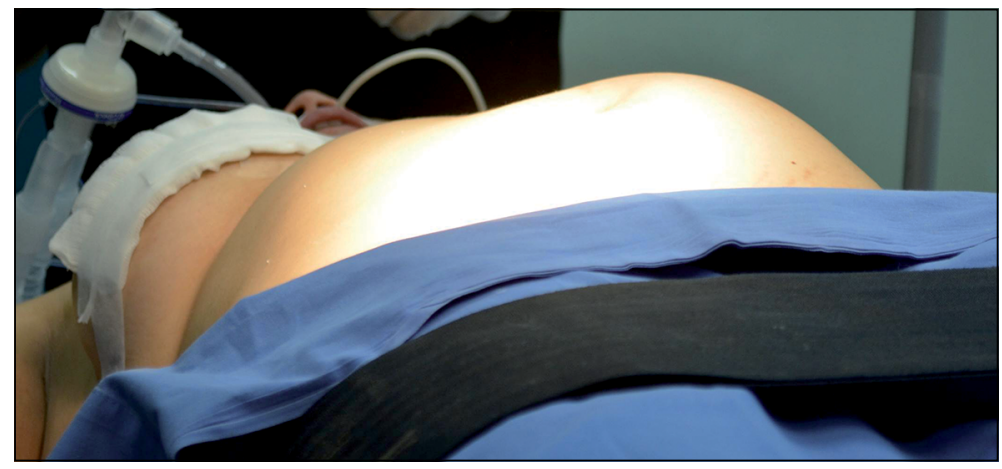

Figura 1. Masa palpable región umbilical. Se observa aumento de volumen abdominal a la inspección, en este caso con asimetría del abdomen.

\footnotetext{
*Recibido el 17 de junio de 2015 y aceptado para publicación el 29 de julio de 2015.
}

Conflictos de interés: Ninguno

Los autores declaran no tener ningún tipo de conflicto de interés en la presentación de este trabajo.

Correspondencia: Dr. Juan Carlos Aguayo R.

jcaguayor@gmail.com 




Figura 2. TC de abdomen que muestra la masa. Tomografía computada. Se observa masa mesentérica de densidad intermedia, única, de $15 \times 15 \mathrm{~cm}$.

con gruesos haces de colágeno grueso, con recuento mitótico mínimo. La paciente evoluciona favorablemente, dada de alta al tercer día postoperatorio. En controles trimestrales no se ha evidenciado recidiva con 17 meses de postoperatorio.

Los tumores desmoides son neoplasias benignas fibroblásticas de muy baja incidencia ${ }^{1}$. Se comportan de una manera localmente agresiva infiltrando el tejido adyacente y con alta incidencia de recidiva local después de la escisión quirúrgica. Además se describe un aumento de la incidencia durante y después del embarazo ${ }^{2}$. Se puede sugerir el diagnóstico a través de la TC ya que generalmente son lesiones sólidas, únicas (10-30\% son múltiples), con densidad similar a la del músculo, sin patrón de refuerzo

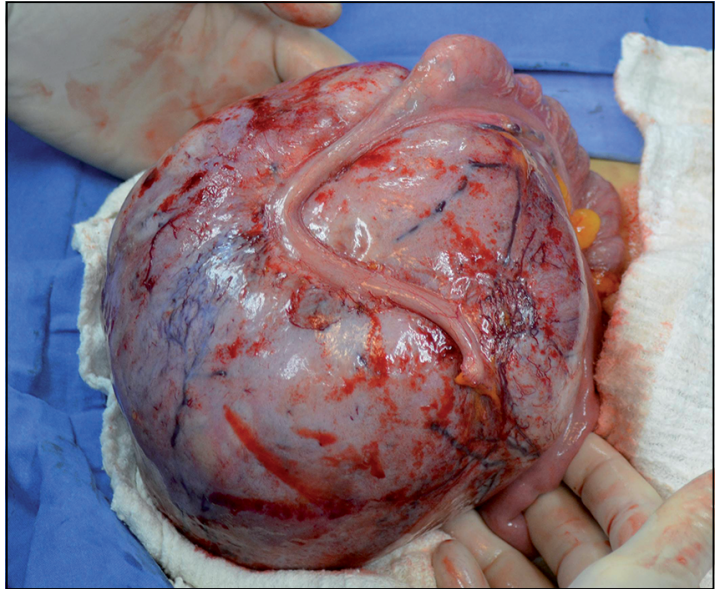

Figura 3. Pieza quirúrgica. Imagen post exéresis de pieza operatoria correspondiente a tumor desmoides cuyo peso fue de $3.000 \mathrm{~g}$.

característico y con márgenes que pueden estar bien o regularmente definidos.

Existe consenso en que el tratamiento quirúrgico es de elección ${ }^{3}$.

\section{Referencias}

1. Montagliani L, Duverger V. Desmoid tumors. J Chir. 2008;145:20-6.

2. İlhan E, Yakan S, Yılmaz C, Şahin T, Cengiz F, Deneçli AG. Mesenteric Fibromatosis in a Postpartum Patient: A Case Report. Surg Chron. 2012;17:114-6.

3. Kasper B, Ströbel P, Hohenberger P. Desmoid Tumors: Clinical Features and Treatment Options for Advanced Disease. The Oncologist 2011;16:682-93. 